\title{
Hubungan Kecemasan terhadap Perawatan Gigi dengan Indeks DMF-T pada Anak Usia 10-12 Tahun di SD Negeri 27 Manado
}

\author{
${ }^{1}$ Uswatun Khasanah \\ ${ }^{1}$ Paulina Gunawan \\ ${ }^{2}$ Herdy Munayang
${ }^{1}$ Program Studi Pendidikan Dokter Gigi Fakultas Kedokteran
${ }^{2}$ Bagian Ilmu Psikiatri Fakultas Kedokteran
Universitas Sam Ratulangi Manado
Email: khasanahuus38@gmail.com

\begin{abstract}
One of the most chronic dental diseases suffered by children is caries. Child anxiety during dental care often becomes a hindrance for dentists in order to give the best or optimum care or treatment. Therefore, it is important for the dentists to have a good relationship with patients, especially children. Childern who have a positive interaction with their dentists could overcome their anxiety, so they will not be afraid to go to the dentist. This study was aimed to analyze the relationship between child anxiety during dental care and DMF-T index among children aged 1012 years old at SDN 27 Manado (elementary school). Subjects were children aged 10-12 years old who had experienced tooth treatment. This was an analytical descriptive study with a crosssectional design. Data were obtained by using Dental Anxiety Scale (DAS) questionnaire and DMF-T examination. The data were analyzed with the Pearson simple correlation test. The results showed that of 40 subjects, 7 children (17.5\%) were not anxious for dental care, 24 children (60\%) were slightly anxious, 7 children $(17.5 \%)$ were anxious, and 2 children $(5.0 \%)$ were very anxious. The DMF-T score 3-5 was the most common, each of 6 children (15\%), meanwhile the most rare was the DMF-T scores of 10 and 15, each of 1 child (2.5\%). The Pearson test of the correlation between anxiety during dental treatment and DMF-T index showed a $P$ of 0.472 . Conclusion: There was no significant correlation between child anxiety for dental care and DMF-T index.
\end{abstract}

Keywords: feeling of anxiety, dental care, DMF-T index

\begin{abstract}
Abstrak: Salah satu penyakit kronis yang paling sering diderita anak ialah karies. Kecemasan anak saat menjalani perawatan gigi sering menjadi penghalang bagi dokter gigi untuk memberikan perawatan yang optimal. Oleh karena itu, penting bagi dokter gigi menjalin hubungan yang baik dengan pasien khususnya pasien anak. Anak yang memiliki interaksi positif terhadap dokter gigi dapat mengatasi rasa cemasnya, sehingga mereka tidak akan takut ke dokter gigi dan memiliki kesehatan gigi dan mulut yang baik. Penelitian ini bertujuan untuk menganalisis hubungan kecemasan terhadap perawatan gigi dengan indeks DMF-T pada anak usia 10-12 tahun di SDN 27 Manado. Subyek penelitian yaitu anak berusia 10-12 tahun yang sudah pernah menerima perawatan gigi sebelumnya. Jenis penelitian ialah deskriptif analitik dengan desain potong lintang. Pengumpulan data menggunakan pengisian kuesioner Dental Anxiety Scale (DAS) dan pemeriksaan DMF-T. Analisis data menggunakan uji korelasi sederhana Pearson. Hasil penelitian menunjukkan dari 40 responden, 7 anak (17,5\%) tidak cemas terhadap perawatan gigi, 24 anak $(60 \%)$ cemas ringan terhadap perawatan gigi, 7 anak $(17,5 \%)$ cemas sedang terhadap perawatan gigi, 2 anak $(5,0 \%)$ cemas berat terhadap perawatan gigi. Skor DMF-T 3-5 merupakan jumlah terbanyak masing-masing 6 anak (15\%), paling sedikit pada skor DMF-T 10 dan 15 masingmasing sebanyak 1 anak (2,5\%). Uji Pearson terhadap hubungan antara perasaan cemas anak terhadap perawatan gigi dengan indeks DMF-T mendapatkan nilai $P=0,472$. Simpulan: Tidak terdapat korelasi antara perasaan cemas anak terhadap perawatan gigi dengan indeks DMF-T.
\end{abstract}

Kata kunci: perasaan cemas, perawatan gigi, indeks DMF-T 
Kesehatan gigi dan mulut merupakan bagian integral dari kesehatan secara keseluruhan yang dapat memengaruhi kualitas hidup seseorang. Prevalensi karies gigi dan penyakit periodontal yang ada dalam lingkungan masyarakat tinggi, khususnya di Indonesia. ${ }^{1}$ National Institute of Health di Amerika Serikat melaporkan bahwa karies gigi menjadi penyakit kronis yang paling sering diderita anak umur 5-17 tahun. ${ }^{2}$ Berdasarkan data World Health Organisation (WHO) tahun 2012, 60-90\% anak-anak sekolah dan hampir $100 \%$ orang dewasa di dunia memiliki karies yang sering menimbulkan rasa sakit serta dapat memengaruhi hidup. ${ }^{3}$

Riset kesehatan dasar (Riskesdas) 2013 tentang prevalensi penyakit gigi dan mulut, menunjukkan bahwa prevalensi penduduk yang bermasalah dengan gigi dan mulut di provinsi Sulawesi Utara yaitu 31,6\% dengan nilai DMF-T 5,4. Hal ini menunjukkan meningkatnya persentase penduduk yang bermasalah dengan gigi dan mulut itu disebabkan karena kurangnya kesadaran masyarakat dalam hal menyikat gigi. ${ }^{4}$ Masalah kesehatan gigi dan mulut yang sering terjadi pada anak ialah karies. ${ }^{1}$

Dalam mengatasi masalah kesehatan gigi dan mulut anak, orang tua harus mampu mengajarkan pada anak tentang kebersihan mulut dan mengajak anak untuk mengunjungi dokter gigi. Kebanyakan anak ketika berkunjung ke tempat praktik dokter gigi kurang kooperatif selama proses perawatan berlangsung, mengakibatkan dokter gigi mengalami kesulitan saat melakukan tindakan perawatan. Terdapat beberapa faktor yang memengaruhi emosional anak di antaranya rasa cemas dan takut selama proses perawatan berlangsung. ${ }^{5}$

Rasa cemas dan takut merupakan salah satu penyebab kegagalan dalam perawatan gigi. Umumnya rasa cemas dan takut timbul akibat perawatan gigi semasa kanakkanak, sehingga pencegahan rasa takut harus dimulai pada usia dini. ${ }^{6}$ Tanggapan negatif anak tentang perawatan gigi dapat menimbulkan rasa takut yang dapat menyebabkan anak menolak untuk melakukan perawatan gigi. Timbulnya rasa takut pada anak merupakan hasil dari tanggapan seorang anak mengenai perawatan gigi melalui pengalaman mendengar cerita dari seseorang. ${ }^{7}$ Rasa takut yang dialami merupakan sugesti dari seorang anak. Sugesti adalah hal yang ditanamkan secara tidak langsung dan secara tidak sadar. Pada anak, sugesti bisa tertanam sangat dalam dan akhirnya sulit untuk dihilangkan. ${ }^{8}$ Rasa takut terhadap perawatan gigi sering dijumpai pada anak di berbagai unit pelayanan kesehatan gigi misalnya di praktik dokter gigi, di rumah sakit maupun puskesmas. ${ }^{9}$

Perasaan takut dan kecemasan yang dialami seorang anak dalam pelayanan kedokteran gigi bukan fenomena yang baru sehingga seorang dokter gigi harus mampu melakukan pendekatan pada anak agar memiliki interaksi positif dan menciptakan suasana kunjungan ke dokter gigi yang lebih menarik dengan melihat dan memahami aspek-aspek yang tidak disukai anak saat mengunjungi dokter gigi. Perlu juga penyesuaian terhadap kebutuhan pasien dengan menyediakan perawatan yang berkualitas untuk mendapatkan kenyamanan agar dapat mengurangi rasa cemas dan takut pasien. Dengan demikian anak-anak akan mengunjungi dokter gigi secara rutin yang berdampak pada lebih baiknya kesehatan gigi dan mulut.

Penelitian yang dilakukan oleh Oba et al. ${ }^{10}$ di Turki menunjukkan bahwa prevalensi kecemasan dental pada anak usia 7-11 tahun memiliki hubungan bermakna terhadap karies yaitu skor kecemasan dental menurun dengan bertambahnya usia. Penelitian ini bertujuan untuk mengetahui hubungan kecemasan terhadap perawatan gigi dengan indeks DMF-T pada anak usia 10-12 tahun di SD Negeri 27 Manado.

\section{METODE PENELITIAN}

Jenis penelitian yang digunakan ialah deskriptif analitik dengan desain potong lintang. Penelitian ini dilaksanakan di SD Negeri 27 Manado berlokasi di Kecamatan Singkil, Manado pada bulan April-Juni tahun 2018.

Populasi dalam penelitian ini ialah seluruh anak usia 10-12 tahun di SD Negeri 
27 Manado dengan jumlah siswa 68 orang. Teknik pengambilan sampel dalam penelitian ini yaitu total sampling.

Pengumpulan data primer berdasarkan hasil kuesioner yang diisi serta hasil pemeriksaan langsung pada anak. Pengumpulan data sekunder dilakukan dengan mengambil data dari pihak sekolah berupa nama lengkap, jenis kelamin, dan umur.

Orang tua/wali sebelumnya diberikan informed consent, kemudian dilakukan pengambilan data anak berupa nama lengkap, jenis kelamin, dan umur akan diminta ke pihak sekolah. Setelah itu anak menjawab lembar kuesioner kecemasan menggunakan Dental Anxiety Scale (DAS). Dengan penilaian skor kecemasan yaitu : A $=1, \mathrm{~B}=2, \mathrm{C}=3, \mathrm{D}=4$, dan $\mathrm{E}=5$ dengan pilihan A menunjukkan pasien santai, B sedikit khawatir, C tegang, D cemas, dan E tingkat maksimum dari kecemasan dental. Penilaian tingkat kecemasan ialah sebagai berikut: Tidak cemas (skor 0-8), kecemasan ringan (skor 9-12), kecemasan sedang (skor 13-14), dan kecemasan berat (skor 15-20). Kemudian dilanjutkan dengan pemeriksaan DMF-T.

Pengolahan data dilakukan menggunakan Statistical Product and Service Solution (SPSS). Untuk melihat distribusi normal masing-masing variabel dilakukan uji normalitas Kolmogorov-Smirnov. Analisis bivariat menggunakan uji korelasi sederhana Pearson untuk menguji hubungan antara variabel bebas dan terikat.

\section{HASIL PENELITIAN}

Sekolah di SD Negeri 27 Manado merupakan salah satu sekolah negeri yang terletak di Singkil Lingkungan 2 Kota Manado, Kelurahan Singkil. Sekolah ini terdiri dari kelas 1-6 dengan jumlah siswa sebanyak 182 anak.

Subyek dalam penelitian ini ialah siswa/i usia 10-12 tahun di SD Negeri 27 Manado dengan jumlah siswa 68 anak dan yang memenuhi kriteria inklusi yaitu berjumlah 40 anak.

Tabel 1 memperlihatkan subyek berjenis kelamin perempuan lebih dominan yaitu sebanyak 21 anak (52,5\%) sedangkan yang berjenis kelamin laki-laki 19 anak (47,5\%).

Tabel 1. Distribusi subyek berdasarkan jenis kelamin

\begin{tabular}{ccc}
\hline $\begin{array}{c}\text { Jenis } \\
\text { kelamin }\end{array}$ & $\begin{array}{c}\text { Jumlah } \\
\text { (n) }\end{array}$ & Persentase \\
\hline Laki-laki & 19 & 47,5 \\
Perempuan & 21 & 52,5 \\
Total & 40 & 100 \\
\hline
\end{tabular}

Tabel 2 menunjukkan bahwa subyek berusia 12 tahun merupakan jumlah tertinggi sebanyak 18 anak (45\%) dan yang paling sedikit didapatkan pada usia 10 dan 11 tahun, masing-masing sebanyak 11 anak $(27,5 \%)$.

Tabel 2. Distribusi subyek berdasarkan usia

\begin{tabular}{ccc}
\hline $\begin{array}{c}\text { Usia } \\
\text { (tahun) }\end{array}$ & $\begin{array}{c}\text { Jumlah } \\
(\mathbf{n})\end{array}$ & Persentase \\
\hline 10 & 11 & 27,5 \\
11 & 11 & 27,5 \\
12 & 18 & 45 \\
Total & 40 & 100 \\
\hline
\end{tabular}

Tabel 3 menampilkan pada kategori cemas ringan sebanyak 24 anak $(60 \%)$ dan paling sedikit pada kategori cemas berat sebanyak 2 anak $(5,0 \%)$.

Tabel 3. Distribusi kecemasan subyek terhadap perawatan gigi

\begin{tabular}{ccc}
\hline Perasaan & $\begin{array}{c}\text { Jumlah } \\
(\mathbf{n})\end{array}$ & Persentase \\
\hline Tidak cemas & 7 & 17,5 \\
Cemas ringan & 24 & 60 \\
Cemas sedang & 7 & 17,5 \\
Cemas berat & 2 & 5,0 \\
Total & 40 & 100 \\
\hline
\end{tabular}

Tabel 4 memperlihatkan bahwa berdasarkan jenis kelamin perempuan paling banyak ditemukan dengan kategori cemas ringan sebanyak 14 anak $(35 \%)$ dan tidak ditemukan pada kategori tidak cemas sedangkan pada jenis kelamin laki-laki paling banyak ditemukan kategori cemas ringan sebanyak 10 anak (25\%) dan paling sedikit dengan kategori cemas sedang dan 
cemas berat masing-masing sebanyak 1 anak $(2,5 \%)$.

Tabel 5 menunjukkan bahwa berdasarkan usia yang paling banyak ditemukan ialah pada usia 12 tahun dengan kategori cemas ringan sebanyak 10 anak (25\%), dan paling sedikit ditemukan pada usia 10 tahun dengan kategori tidak cemas dan cemas sedang masing-masing sebanyak 1 anak $(2,5 \%)$, dan tidak ditemukan pada kategori cemas berat pada usia 11 dan 12 tahun.

Tabel 4. Distribusi kecemasan subyek berdasarkan jenis kelamin

\begin{tabular}{ccccccccccc}
\hline Jenis & \multicolumn{2}{c}{ TC } & \multicolumn{2}{c}{ CR } & \multicolumn{2}{c}{ CS } & \multicolumn{2}{c}{ CB } & \multicolumn{2}{c}{ Total } \\
kelamin & $\mathrm{n}$ & $\%$ & $\mathrm{n}$ & $\%$ & $\mathrm{n}$ & $\%$ & $\mathrm{n}$ & $\%$ & $\mathrm{n}$ & $\%$ \\
\hline $\mathrm{L}$ & 7 & 17,5 & 10 & 25 & 1 & 2,5 & 1 & 2,5 & 19 & 47,5 \\
$\mathrm{P}$ & 0 & 0 & 14 & 35 & 6 & 15 & 1 & 2,5 & 21 & 52,5 \\
Total & 7 & 17,5 & 24 & 60 & 7 & 17,5 & 2 & 5 & 40 & 100 \\
\hline
\end{tabular}

Tabel 5. Distribusi kecemasan subyek berdasarkan usia

\begin{tabular}{ccccccccccc}
\hline $\begin{array}{c}\text { Usia } \\
\text { (tahun) }\end{array}$ & \multicolumn{2}{c}{ TC } & $\%$ & \multicolumn{2}{c}{ CR } & \multicolumn{2}{c}{ CS } & \multicolumn{2}{c}{ CB } & \multicolumn{2}{c}{ Total } \\
\hline 10 & 1 & 2,5 & 7 & 17,5 & 1 & 2,5 & 2 & 5 & 11 & 27,5 \\
11 & 2 & 5 & 7 & 17,5 & 2 & 5 & 0 & 0 & 11 & 27,5 \\
12 & 4 & 10 & 10 & 25 & 4 & 10 & 0 & 0 & 18 & 45 \\
Total & 7 & 17,5 & 24 & 60 & 7 & 17,5 & 2 & 5 & 40 & 100 \\
\hline
\end{tabular}

Tabel 6 menunjukkan bahwa skor DMF-T 3-5 merupakan jumlah terbanyak masing-masing 6 anak (15\%), paling sedikit pada skor DMF-T 10 dan 15 masing-masing sebanyak 1 anak $(2,5 \%)$; tidak ditemukan skor DMF-T 11-14.

Tabel 6. Distribusi Skor DMF-T

\begin{tabular}{ccc}
\hline $\begin{array}{c}\text { Skor } \\
\text { DMF-T }\end{array}$ & $\begin{array}{c}\text { Jumlah } \\
(\mathbf{n})\end{array}$ & Persentase \\
\hline 0 & 5 & 12,5 \\
1 & 2 & 5 \\
2 & 3 & 7,5 \\
3 & 6 & 15 \\
4 & 6 & 15 \\
5 & 6 & 15 \\
6 & 2 & 5 \\
7 & 4 & 10 \\
8 & 2 & 5 \\
9 & 2 & 5 \\
10 & 1 & 2,5 \\
11 & 0 & 0 \\
12 & 0 & 0 \\
13 & 0 & 0 \\
14 & 0 & 0 \\
15 & 1 & 2,5 \\
Total & 40 & 100 \\
\hline
\end{tabular}

Tabel 7 menunjukkan bahwa skor DMF-T 4-7 merupakan jumlah terbanyak yaitu 18 anak (45\%), dan paling sedikit pada skor $12-15$ sebanyak 1 anak $(2,5 \%)$.

Tabel 7. Distribusi pengelompokan skor DMF$\mathrm{T}$

\begin{tabular}{ccc}
\hline Skor DMF-T & $\begin{array}{c}\text { Jumlah } \\
(\mathbf{n})\end{array}$ & Persentase \\
\hline $0-3$ & 16 & 40 \\
$4-7$ & 18 & 45 \\
$8-11$ & 5 & 12,5 \\
$12-15$ & 1 & 2,5 \\
Total & 40 & 100 \\
\hline
\end{tabular}

Tabel 8 menunjukkan bahwa kecemasan pada kategori cemas ringan menempati posisi tertinggi dengan skor DMF-T masing-masing 0-3 sebanyak 11 anak (27,5\%), skor DMF-T 4-7 sebanyak 9 anak (22,5\%), skor DMF-T 8-11 sebanyak 4 anak (10\%), dan tidak ditemukan pada kategori cemas berat dengan skor DMF-T 8-11 dan 12-15. 
Jurnal e-GiGi (eG), Volume 6 Nomor 2, Juli-Desember 2018

Tabel 8. Hubungan kecemasan terhadap perawatan gigi dengan DMF-T

\begin{tabular}{ccccccccccc}
\hline $\begin{array}{c}\text { Perasaan } \\
\text { cemas }\end{array}$ & \multicolumn{2}{c}{$\mathbf{0}$} & \multicolumn{9}{c}{ Skor DMF-T } & \multicolumn{2}{c}{$\mathbf{1 2 - 1 5}$} & \multicolumn{2}{c}{ Total } \\
& $\mathrm{n}$ & $\%$ & $\mathrm{n}$ & $\%$ & $\mathrm{n}$ & $\%$ & $\mathrm{n}$ & $\%$ & $\mathrm{n}$ & $\%$ \\
\hline Tidak cemas & 1 & 2,5 & 5 & 12,5 & 0 & 0 & 1 & 2,5 & 7 & 17,5 \\
Cemas ringan & 11 & 27,5 & 9 & 22,5 & 4 & 10 & 0 & 0 & 24 & 60 \\
Cemas sedang & 3 & 7,5 & 3 & 7,5 & 1 & 2,5 & 0 & 0 & 7 & 17,5 \\
Cemas berat & 1 & 2,5 & 1 & 2,5 & 0 & 0 & 0 & 0 & 2 & 5 \\
Total & 16 & 40 & 18 & 45 & 5 & 12,5 & 1 & 2,5 & 40 & 100 \\
\hline
\end{tabular}

\section{BAHASAN}

Telah dilakukan penelitian mengenai hubungan kecemasan anak terhadap perawatan gigi dengan karies di SD Negeri 27 Manado. Sebanyak 40 anak yang memenuhi kriteria inklusi diberikan kuesioner kecemasan terhadap perawatan gigi dan pemeriksaan DMF-T. Berdasarkan jenis kelamin, perempuan merupakan jumlah terbanyak 21 anak $(52,5 \%)$ dengan persentase yang mengalami kategori cemas ringan sebanyak 35\% sedangkan laki-laki sebanyak 19 anak (47,5\%) dengan persentase yang mengalami kategori cemas ringan sebanyak $25 \%$ (Tabel 4). Hal ini sejalan dengan penelitian yang dilakukan oleh Rehatta et al. ${ }^{11}$ di kota Manado yang menunjukkan bahwa jenis kelamin secara bermakna berpengaruh terhadap tingkat kecemasan dan didapatkan pula bahwa pasien berjenis kelamin perempuan lebih cemas dibandingkan laki-laki yaitu sebesar 28 sampel $(50,91 \%)$.

Hasil pemeriksaan kecemasan menurut usia (Tabel 5) mendapatkan subyek paling banyak pada usia 12 tahun dengan kategori cemas ringan sebanyak 10 anak (25\%) dan yang paling sedikit pada usia 10 tahun dengan kategori tidak cemas dan cemas sedang masing-masing sebanyak 1 anak $(2,5 \%)$, dan tidak ditemukan pada kategori cemas berat pada umur 11 dan 12 tahun. Hasil ini sejalan dengan penelitian yang dilakukan Oba et al. ${ }^{10}$ pada 275 anak yang berusia 7-11 tahun tentang prevalensi kecemasan dental anak dan hubungannya dengan karies bahwa kecemasan dental terjadi pada usia 7-11 tahun, dan kecemasan dental berkurang seiring dengan meningkatnya usia.
Hasil penelitian berdasarkan skor DMF-T (Tabel 6) menunjukkan bahwa skor DMF-T 3-5 merupakan jumlah terbanyak masing-masing 6 anak (15\%), paling sedikit pada skor DMF-T 10 dan 15 masing-masing sebanyak 1 anak $(2,5 \%)$, dan tidak ditemukan pada skor DMF-T 1114. Tabel 7 menunjukkan bahwa skor DMF-T 4-7 merupakan jumlah terbanyak yaitu 18 anak (45\%), dan paling sedikit pada skor $12-15$ sebanyak 1 anak $(2,5 \%)$. Hal ini dikarenakan anak yang takut dengan dokter gigi memiliki kesehatan rongga mulut yang rendah dengan angka kejadian karies yang tinggi, ${ }^{12}$ dan kecemasan dental juga memiliki efek negatif terhadap kebersihan mulut yang dapat meningkatkan index DMF-T. ${ }^{13}$

Berdasarkan hasil penelitian ditemukan kategori cemas ringan menempati posisi tertinggi dengan skor DMF-T masingmasing 0-3 sebanyak 11 anak (27,5\%), posisi terendah ditemukan pada kategori cemas berat dengan skor DMF-T 0-3 dan 4-7 masing-masing sebanyak 1 orang $(2,5)$ (Tabel 8). Hasil penelitian hubungan kecemasan terhadap perawatan gigi dengan indeks DMF-T pada anak usia 10-12 tahun di SD Negeri 27 Manado menunjukkan bahwa tidak terdapat hubungan bermakna antara kecemasan dan index DMF-T. Hasil pengujian dengan menggunakan uji korelasi sederhana Pearson mendapatkan nilai $P$ $>0,05(P=0,472)$. Hal ini sejalan dengan penelitian yang dilakukan oleh Jatiningrum et al. ${ }^{14}$ pada 65 anak berusia 9-12 tahun di klinik kedokteran gigi anak FKG UGM tentang hubungan antara kecemasan dental dengan status karies gigi yang menyatakan bahwa tidak terdapat hubungan bermakna 
antara kecemasan dental dengan indeks DMF-T pada anak dengan nilai $P=0,63$.

\section{SIMPULAN}

Berdasarkan hasil penelitian dan bahasan dapat disimpulkan bahwa tidak terdapat hubungan bermakna antara kecemasan terhadap perawatan gigi dengan DMF-T pada anak usia 10-12 tahun di SD Negeri 27 Manado.

\section{SARAN}

Disarankan agar pihak sekolah perlu menerapkan Usaha Kesehatan Gigi Sekolah (UKGS) agar dapat tercipta perilaku serta kebiasaan yang baik untuk menjaga kesehatan gigi dan mulut. Diharapkan peran orang tua untuk membiasakan anak melakukan kunjungan berkala ke dokter gigi sejak dini minimal 6 bulan sekali, sehingga anak terbiasa dengan perawatan gigi dan dapat mengendalikan rasa takut terhadap dokter gigi. Dokter gigi diharapkan bersikap lebih ramah, memberi kesan menarik, dan mengakrabkan diri dengan pasien anak agar terjalin rasa percaya dan dapat mengurangi rasa takut pada anak.

\section{DAFTAR PUSTAKA}

1. Notohartojo IT, Ghani L. Pemeriksaan karies gigi pada beberapa kelompok usia oleh petugas dengan latar belakang berbeda di Provinsi Kalimantan Barat. Buletin Penelitian Kesehatan. 2015; 43(4):h.258.

2. Alaki S, Alotaibil A, Almabadi E, Alanquri E. Dental anxiety in middle school children and their caregivers: prevalence and severity. J Dent Oral Hyg. 2012;4(1):6-11 .

3. World Health Organization Oral Health Survey. Basic Method (4th ed). Geneva: WHO, 2012; p. 7.

4. Riset Kesehatan Dasar (RISKESDAS). Status Gizi. Jakarta: Kementerian Kesehatan RI, 2013; p. 15.

5. Mittal R, Sharma M. Assessment of psychological effects af dental treatmant on children. Contempory
Clinical Dentistry. 2012;3. [cited 2018 March 1]. Available from: http: // www.contempclindent.org/temp/Conte mpClinDent3529994998_024634.pdf. p. 2.

6. Hamidah N, Didit A, Cholil. Peranan penyuluhan demonstrasi terhadap rasa takut dan cemas anak selama perawatan gigi di Puskesmas Cempaka Putih Banjarmasin. Dentino. 2014;(2):34-8.

7. Andriana DP, Wiworo H, Aryani W. Pengaruh pemberian komunikasi terapeutik dan tanpa komunikasi terapeutik terhadap rasa takut pada pencabutan gigi usia 8-11 tahun. Gigi dan Mulut. 2016;(3):46-9.

8. Erwana FA. Seputar Kesehatan Gigi Dan Mulut. Jogjakarta: Rapha Publishing, 2013; p. 67.

9. Amrullah AA. Tingkat kecemasan anak sekolah dasar usia 6-12 tahun terhadap perawatan gigi [Skripsi]. Makassar: Fakultas Kedokteran Gigi Universitas Hasanuddin; 2012.

10. Oba AA, Dulgergil CT, Sonmez IS. Prevalence of dental anxiety in 7-11 year old children and its relationship to dental caries. Med Princ Pract. 2009; 18:453-7.

11. Rehatta V, Gunawan P, Kandou J. Gambaran kecemasan pencabutan gigi anak di puskesmas Bahu Manado. eG. 2014;2(2):1-6.

12. Munevv A, Akgol B, Erol T. Assessment of the feelings and attitudes of children towards their dentist and their association with oral health. ISRN Dentistry. 2014. Article ID 867234. p.1.

13. Khraisat H, Olaimat AA. Dental anxiety and its possible effects on caries prevalence among a group. JRMS. 2013;20(2);26-31.

14. Jatiningrum RM, Pamardiningsih $Y$, Widiati S. Hubungan antara kecemasan dental dengan status karies gigi pada anak usia 9-12 tahun di Klinik Kedokteran Gigi Anak Fakultas Kedokteran Gigi Universitas Gadjah Mada. Yogjakarta: Universitas Gadjah Mada; 2014; p. xvi. 